\title{
Narrativa da Doença: Uma Disciplina Optativa na Faculdade de Medicina de Lisboa
}

\section{Narrative Medicine: An Optative Course at the Faculty of Medicine of Lisbon}

Maria do Céu MACHADO $\varangle^{1}$, João LOBO ANTUNES ${ }^{2}$

Acta Med Port 2016 Dec;29(12):790-792 - http://dx.doi.org/10.20344/amp.8284

Palavras-chave: Cuidados Centrados no Doente; Educação Médica Pré-Graduada; Empatia; Narrativa.

Keywords: Education, Medical, Undergraduate; Empathy; Narration; Patient-Centered Care.

\section{Enquadramento}

A chamada 'Medicina Narrativa' surgiu nos anos 90, na educação e na prática médica americana com o objetivo de desenvolver a aptidão dos estudantes para reconhecer o sofrimento, interpretar e ser sensibilizado pela história da doença. ${ }^{1}$

Os métodos propostos incluíam a leitura de textos literários, colheita da história clínica tutorada e escrita reflexiva que facilitem e estimulem uma relação de empatia e respeito entre o médico e o doente e daquele com os outros profissionais de saúde.

A Literatura e a Medicina são complementares pois o texto literário não é apenas um instrumento de cultura para o médico e as estórias da medicina serão mais do que uma fonte de enredo para o romancista. ${ }^{2}$ De igual modo, o método que o médico utiliza para interpretar de forma correcta o que o doente sente não é muito diferente do que usa o leitor na compreensão do texto literário.

A medicina narrativamente competente envolve simultaneamente três aspetos fundamentais: a história clínica, a escrita compreensiva e a empatia com o doente. A história da doença, aceitando sem julgamento o testemunho de quem sofre é um elemento fundamental na boa prática clínica que fatores como a hiperespecialização e a expansão da tecnologia constantemente ameaçam. A escrita compreensiva torna o doente visível como pessoa e a empatia potencia a capacidade de sentir o sofrimento.

Muitas escolas médicas anglo-saxónicas incluem o treino de humanidades, ciências sociais e arte no currículo do $2^{\circ}$ ano, ${ }^{3}$ o que também acontece na Faculdade de Medicina da Universidade de Lisboa que introduz alguns destes tópicos nas disciplinas do primeiro ciclo do Mestrado Integrado de Medicina, o que é fundamental para uma sensibilização precoce do jovem estudante mas deve ser complementada numa fase mais tardia quando os alunos têm outra maturidade e experiência e começam a conhecer a complexidade do encontro singular da clínica.

Com esta convicção, os autores propuseram a criação de uma disciplina optativa designada por 'Narrativa da
Doença' para um grupo limitado de estudantes do quarto e quinto ano com o objetivo de colher, dessa forma, ensinamentos para um projeto mais ambicioso.

\section{A Narrativa da Doença como disciplina optativa}

O currículo do Mestrado Integrado de Medicina inclui disciplinas de opção, definidas por 20 horas de contacto e oito horas de estudo, com o objetivo de aprofundar conhecimentos em áreas disciplinares que pela sua diferenciação sejam motivo de curiosidade e prospeção motivacional. O regulamento das disciplinas optativas permite limitar o número de vagas e os alunos escolhem livremente, não é exigida avaliação e a presença participativa confere a aprovação e um crédito.

A disciplina optativa 'Narrativa da Doença', aprovada pelo Conselho Científico, tinha cinco objetivos: i) desenvolver a competência narrativa; ii) aprender estratégias de comunicação; iii) adquirir aptidão para reconhecer, interpretar e ser sensibilizado pela história da doença; iv) conhecer narrativas da doença através de testemunhos literários; v) adquirir hábitos de prática reflexiva.

O programa desenvolvido durante uma semana implicava formação teórica e painéis de discussão e foi proposta com o acordo dos alunos a realização de um trabalho de campo e seminário final de discussão. A Tabela 1 mostra os conteúdos programáticos e a metodologia assim como os docentes de diferentes áreas.

A componente prática exigia que os alunos observassem e vivenciassem o sofrimento e foi tutorada individualmente na Urgência Geral e Cuidados Intensivos, num período mínimo de 4 horas, entre as 16 horas e as 24 horas. Foi pedido aos alunos que estivessem mais atentos ao sofrimento do que à patologia.

A avaliação foi efetuada através da leitura e discussão em plenário de dois trabalhos escritos um dos quais a apreciação de um texto literário e outro, o relatório da componente prática na urgência.

Inscreveram-se, no curso de fevereiro de 2013, 12 alunos do quarto e quinto ano. Compareceram às aulas oito,

1. Professora. Faculdade de Medicina. Universidade de Lisboa. Lisboa. Portugal.

2. Professor Emérito. Faculdade de Medicina. Universidade de Lisboa. Lisboa. Portugal.

$\bowtie$ Autor correspondente: Maria do Céu Machado. machadomariaceu@gmail.com

Recebido: 10 de outubro de 2016 - Aceite: 23 de novembro de 2016 | Copyright $\odot$ Ordem dos Médicos 2016 
Tabela 1 - Programa de Narrativa da Doença

\begin{tabular}{|c|c|c|c|c|}
\hline Conteúdos programáticos & Intervenientes & Metodologia & Textos de apoio & Horas \\
\hline $\begin{array}{c}\text { Empatia, testemunho e narrativa } \\
\text { da doença }\end{array}$ & João Lobo Antunes & $\begin{array}{l}\text { Discussão de textos } \\
\text { literários }\end{array}$ & $\begin{array}{c}\text { A caneta que escreve e } \\
\text { a que prescreve }\end{array}$ & 2 \\
\hline $\begin{array}{l}\text { Expressão literária da dor e } \\
\text { sofrimento }\end{array}$ & António Lobo Antunes & Diálogo reflexivo & Sôbolos rios que vão & 2 \\
\hline Dimensão espiritual da doença & Mons Vitor Feytor Pinto & Diálogo reflexivo & & 2 \\
\hline Evolução do conceito de doença & Manuel Silvério Marques & & & 2 \\
\hline O adolescente e o sigilo médico & Daniel Sampaio & $\begin{array}{l}\text { Discussão de situações } \\
\text { clínicas }\end{array}$ & & 2 \\
\hline $\begin{array}{c}\text { A doença e a pessoa em todas } \\
\text { as dimensões da sua dignidade - } \\
\text { a clínica do dia-a-dia }\end{array}$ & Maria do Céu Machado & $\begin{array}{l}\text { Discussão de situações } \\
\text { clínicas e leitura reflexiva }\end{array}$ & How doctors think & 4 \\
\hline $\begin{array}{c}\text { Doença, vida pessoal do doente } \\
\text { e papel do médico }\end{array}$ & João Lobo Antunes & $\begin{array}{l}\text { Experiência e } \\
\text { leitura reflexiva }\end{array}$ & $\begin{array}{l}\text { - De Profundis. } \\
\text { A Valsa lenta. } \\
\text { - L'hôpital et la loi } \\
\text { morale. }\end{array}$ & 2 \\
\hline Prática & Tutores individuais & & & Mínimo 4 \\
\hline Painel de discussão & $\begin{array}{c}\text { M Céu Machado/ } \\
\text { João Lobo Antunes e } \\
\text { estudantes }\end{array}$ & & $\begin{array}{l}\text { Escrita criativa e } \\
\text { relatórios dos dos } \\
\text { estudantes }\end{array}$ & 3 \\
\hline
\end{tabular}

Fontes: Crabbé Rocha C. A caneta que escreve e a que prescreve. Lisboa: Edição Verbo; 2012; Lobo Antunes A. Sôbolos rios que vão. Lisboa: Dom Quixote; 2010; Groopman J. How doctors think. New York: Houghton Mifflin; 2007; Cardoso Pires J. De profundis, valsa lenta. Lisboa: Dom Quixote; 1997; Gil F. L'hôpital et la loi morale. Revue Rue Descartes. 2010;68(2).

e seis completaram a formação com discussão de relatório reflexivo no seminário final. Foram aprovados seis alunos.

A opinião unânime foi de que as atividades desenvolvidas tinham contribuído para uma maior maturidade como estudantes de medicina e para a compreensão da situação vivida por cada doente. Alguns relatórios refletem a consciencialização de uma atitude diferente de que se transcrevem os seguintes excertos:

- LC, aluno: “... pergunta-me uma das doentes se já é de noite. Apesar de serem seis e meia da tarde, limitei-me a dizer-lhe que já deveria estar a escurecer. Aqui não se distingue o dia da noite. As luzes nunca se apagam. Ouve-se um burburinho infindável e sente-se uma agitação incessante. ... percebi que o sofrimento é experienciado pelas pessoas e não pelos corpos ao contrário das doenças."

- DA, aluna: “... a história clínica, registada em formato padrão, tem o tom rotineiro dos registos oficiais e burocráticos, cujos narradores são apagados e cujas nuances acabam por se tornar fixas e objectivas. A experiência do doente é codificada num diagrama lógico, onde as irrelevâncias são eliminadas e os conceitos fisiopatológicos inerentes são iluminados. Por um outro ponto de vista, trata-se de uma conversão do sofrimento do doente numa versão medicamente reconhecível e fiável. ... A medicina baseada na narrativa honra, desenvolve e potencializa o encontro clínico. Foi o que retirei de toda uma semana de histórias contadas, ideias trocadas e baralhadas. $E$ foi isso que tentámos fazer, todos nós, por algumas horas em cada canto onde ficámos. Porque, embora a doença seja um evento biológico e objectivamente material, a resposta humana a esse fenómeno não é biologicamente observável ou aritmeticamente traduzível."

- AS, aluna: “... estava deste lado com o tutor, mas ouvia-se tudo o que se passava do outro lado da cortina. Incomodou-me profundamente a atitude e tom de voz aplicado aos doentes. A médica falava num tom abrasivo e impaciente demonstrando uma atitude superior. Quando os doentes começavam a sua narrativa, interrompia-os constantemente e fazia uma série rápida de perguntas dirigidas, não permitindo ao doente contar minimamente a sua história."

- TS, aluno: “... com esta experiência compreendi que ser médico é também algo que a Faculdade de Medicina não pode ensinar, pode apenas dar-nos a oportunidade de aprender. Pode nascer com a pessoa, aprende-se com o tempo e matura-se com a experiência. A gestão de sensibilidades e sentimentos humanos é muito lábil, mas o médico deve tentar fazê-la da melhor forma para o bem do doente. Tenho a agradecer à tutora tudo o que me ensinou nesta breve tarde, mesmo sem se ter apercebido disso, e que espero pôr em prática da melhor forma, humana, com compaixão, ao longo da minha vida profissional e pessoal."

\section{Comentários e proposta}

No ensino da Medicina sente-se a necessidade de um contra peso ao reducionismo da técnica, da superespecialização mas por outro lado, a evolução da reflexão ética e do respeito pela pessoa e a cultura da segurança pelas instituições, tornou inadmissível o treino desordenado e 
exaustivo em doentes internados.

Procuraram-se outros métodos, nomeadamente as técnicas de simulação como o role play que estimula e desenvolve a capacidade de ouvir, de transmitir informação adequada e de interpretar a linguagem corporal. ${ }^{4}$ Apesar de ter sido provada a eficácia da aprendizagem, estes modelos podem criar uma falsa sensação quando aplicados ao discurso do doente, cheio de detalhes e subtilezas, e condicionam os estudantes a aplicar estereótipos em vez de compreender atitudes. O diálogo entre o doente e a família e o médico pode ser estruturado mas a interação é sempre improvisada e exige preparação para a imprevisibilidade.

A Medicina Narrativa é um dos métodos de ensino que utiliza um processo interdisciplinar na abordagem ao sofrimento e à doença e relação terapêutica e surge como disciplina intelectualmente híbrida com Rita Charon, cujo mérito foi a abordagem pela literatura. ${ }^{5}$

A experiência de uma disciplina optativa de Medicina Narrativa na Faculdade de Medicina de Lisboa no segundo ciclo foi positiva segundo os testemunhos dos alunos e motivo de satisfação para os docentes. Muito embora seja importante a aprendizagem precoce da comunicação médico-doente, o interrogatório conduzido pelos alunos torna-se, nos últimos anos, mais focado nos sintomas como se, à medida que adquirem conhecimentos científicos, percam

\section{REFERÊNCIAS}

1. Charon R. Narrative Medicine. A model for empathy, reflection, profession and trust. JAMA. 2001;286:1897-902.

2. Charon R. Literature and Medicine: Origins and Destinies. Acad Med. 2000;75:23-7

3. Miller E, Balmer D, Hermann N, Graham G, Charon R. Sounding narrative medicine: studying students' professional identity development at Columbia University College Of Physicians and Surgeons. Acad Med. 2014;89:335-42.

4. Accreditation Council for Graduate Medical Education. Outcome Project. Chicago: ACGME; 2011. qualidades humanas. Há evidência de que o aluno inexperiente tem um diálogo mais empático, na procura de fatores psicológicos e sociais, em contraste com a entrevista mais estruturada, mais seca do aluno mais avançado. ${ }^{6}$

Parece, assim, que estas competências devem ser desenvolvidas ao longo do curso e não apenas nos primeiros anos ou como opção de 20 horas. O conceito de Medicina Narrativa é mais do que uma disciplina, é uma área de comunicação, colaboração e profissionalismo que exige treino na prática médica e capacidades de relacionamento interpessoal, ético, interpretativo e reflexivo. ${ }^{7,8} \mathrm{O}$ docente clínico deve ter formação na área e ser o modelo na forma como colhe uma história clínica e no relacionamento com o doente e a família.

Como refere João Lobo Antunes, "a profissão de médico aprende-se de uma forma estruturada por um currículo formal e de uma forma caótica, inesperada, por um currículo escondido. O currículo escondido é alimentado sobretudo por modelos, que se definem por qualidades que incluem compaixão, sentido de humor, integridade, aptidões docentes como a capacidade de explicar, com clareza e de forma não intimidante, assuntos complexos, proficiência na arte de diagnosticar e tacto na relação com os doentes e familiares". 9

5. Lobo Antunes J. Ouvir com outros olhos. Lisboa: Edição Gradiva; 2015.

6. Davis H, Nicholaou T. A comparison of the interviewing skills of first- and final-year medical students. Med Educ. 1992;26:441-7.

7. Arntfield S, Slesar K, Dickson J, Charon R. Narrative medicine as a mean of training medical students toward residency competences. Patient Educ Counsel. 2013;91:280-6.

8. Charon R. Narrative medicine: honoring the stories of illness. Oxford: Oxford University Press; 2006.

9. Lobo Antunes J. O currículo escondido. In memória de Nova lorque e outros ensaios. Lisboa: Edição Gradiva; 2002 